\begin{tabular}{|c|l|}
\hline Title & Fundamental Study of InP-Based Open-Gate Field-Effect Transistors for A pplication to Liquid-Phase Chemical Sensors \\
\hline Author(s) & Yoshizawa, Naoki; Sato, Taketomo; Hashizume, Tamotsu \\
\hline Citation & $\begin{array}{l}\text { Japanese Journal of A pplied Physics, 48(9), 091102 } \\
\text { https://doi.org/40.1143/JAP.48.091102 }\end{array}$ \\
\hline Issue Date & 2009-09 \\
\hline Doc URL & http://hdl.handle.net/2115/42586 \\
\hline Rights & ○ 2009 The Japan Society of A pplied Physics \\
\hline Type & article (author version) \\
\hline File Information & JJA P48_091102.pdf \\
\hline
\end{tabular}

Instructions for use 


\section{Fundamental Study of InP-Based Open-Gate Field Effect Transistors for Application to Liquid-Phase Chemical Sensors}

Naoki Yoshizawa, Taketomo Sato, and Tamotsu Hashizume

Research Center for Integrated Quantum Electronics, and Graduate School of Information Science and Technology, Hokkaido University, N-13, W-8, Kita-ku, Sapporo 060-8628, Japan

We prove with this paper that InP-based open-gate Field Effect Transistors (FETs) work well as liquid-phase chemical sensors. The open-gate FET clearly exhibited current saturation and a pinch-off behavior in the electrolyte, resulting in a rapid response to the gate bias applied via the electrolyte. A series of sensing measurements showed that the surface potential of the InP linearly changed with the $\mathrm{pH}$ values of the electrolytes in a $\mathrm{pH}$ range from 3.0 to 12.0 . The $\mathrm{pH}$ sensitivity of the open-gate FETs depended on the ion species contained in the electrolyte. $\mathrm{A} \mathrm{Si}_{3} \mathrm{~N}_{4}$ layer was useful as an ion selective membrane for the InP open-gate FETs to improve the selectivity of $\mathrm{H}^{+}$ions.

\section{Introduction}

A liquid-phase chemical sensor that is based on an ion-sensitive field-effect transistor (ISFET) is one of the most promising instruments for biochemical sensing. Since ISFETs are electronic devices that detect potential changes in the gate area with a current signal, they are applied to various biochemical sensors by employing specific ion-selective membranes. ISFETs in $\mathrm{pH}$ and glucose sensors are common examples of their applications where they have many advantages over conventional amperometric sensors, such as short response times, miniaturization, and high-density integration.

Liquid-phase sensors based on ISFETs have been extensively studied for $\mathrm{Si}$ metal-oxide-semiconductor (MOS) structures ${ }^{1,2)}$. Significant research efforts have been devoted on designing a device structure for improving the sensitivity and stability by changing the gate insulators $^{3-5)}$. Another approach for improving the device performance is to use compound semiconductors as substrate materials. In particular, for III-V compound semiconductors such as InP-, GaAs-, and GaN-related materials, drastic improvement in sensitivity is expected because of their superb electrical properties. Recently, ISFETs that are based on high electron mobility transistors (HEMTs) have demonstratively shown the capabilities of III-V compound materials for use in various liquid-phase sensors ${ }^{6-8)}$. 
The purpose of this study is to investigate the feasibility of liquid-phase chemical sensors that are based on InP open-gate FETs. InP has been attracting attention as a sensor material due to its surface sensitive nature. Various gas sensors that form on n-type InP have been recently reported, such as $\mathrm{H}_{2}$ gas sensors ${ }^{9,10)}$ and $\mathrm{NO}_{2}$ gas sensors ${ }^{11)}$. In this study, we show that InP-based open-gate FETs work well as $\mathrm{pH}$ sensors in various electrolytes.

\section{Experimental Procedure}

An n-type InP epitaxial layer with a thickness $(a)$ of $200 \mathrm{~nm}$ was grown on a Fe-doped semi-insulating (001) InP substrate to fabricate an open-gate FET. Hall measurements showed that the carrier concentration $\left(N_{\mathrm{D}}\right)$ was $8 \times 10^{16} \mathrm{~cm}^{-3}$ and the mobility $(\mu)$ was $2700 \mathrm{~cm}^{2} \mathrm{~V}^{-1} \mathrm{~s}^{-1}$. As shown in Fig. 1, source and drain ohmic contacts were formed on mesa-etched islands on the InP epitaxial layers by depositing the GeAuNi layers and annealing them at $400^{\circ} \mathrm{C}$ for $5 \mathrm{~min}$. Then, a 100-nm-thick $\mathrm{SiO}_{2}$ film was deposited on the surface using plasma-enhanced chemical vapor deposition (PECVD) at $300^{\circ} \mathrm{C}$. Finally, the open-gate window that was $10 \mu \mathrm{m}$ in length $\left(L_{\mathrm{G}}\right)$ and a $125 \mu \mathrm{m}$ in width $\left(W_{\mathrm{G}}\right)$ was formed by using standard photolithography and etching processes, as shown in the inset photograph in Fig. 1.

Figure 2 shows the experimental setup used in this study for a series of electrochemical measurements. The open gate FETs were set on a Tefron holder, and the source and drain electrodes were connected to the outer circuit via the embedded wires. The top surface except for the open-gate area was covered by an epoxy or negative-type photoresist. The gate bias was applied with a semiconductor parameter analyzer to the electrolyte/InP interface at the open-gate area via a saturated calomel electrode (SCE). For a series of $\mathrm{pH}$-sensing measurements, a $0.01-\mathrm{M} \mathrm{KCl}$ solution was added as a base electrolyte, and $\mathrm{HCl}, \mathrm{H}_{3} \mathrm{PO}_{4}$, and $\mathrm{NaOH}$ solutions were used for the $\mathrm{pH}$ control. The $\mathrm{pH}$ values of the electrolytes were measured using a digital $\mathrm{pH}$-meter after calibration with standard reference solutions.

\section{Results and Discussion}

\subsection{Basic properties of open-gate FETs in an electrolyte}

In order to clarify the basic properties of open-gate FETs, source drain current voltage $\left(I_{\mathrm{ds}}-V_{\mathrm{ds}}\right)$ measurements were first carried out by changing the gate potential, $V_{\mathrm{gs}}$. Figure 3 shows some typical $I_{\mathrm{ds}}-V_{\mathrm{ds}}$ characteristics of an open-gate FET measured in a $0.1-\mathrm{M}$ phosphate buffer solution (PBS) with a $\mathrm{pH}$ of 7.0 in the dark. The device clearly exhibited current saturation and pinch-off behaviors just like conventional Schottky-gate FETs. The result indicates that the depletion layer was formed underneath the open-gate and it suppresses the current flow from the source to the drain contacts. 
In a similar fashion as that in conventional Schottky-gate FETs, the source-drain currents, $I_{\mathrm{ds}}$, of open-gate FETs can be described by the gradual channel approximation using the following equation:

$$
I_{\mathrm{ds}}=I_{\mathrm{p}}\left\{\frac{3 V_{\mathrm{ds}}}{V_{\mathrm{p}}}-2\left[\frac{\left(V_{\mathrm{ds}}+V_{\mathrm{bi}}-V_{\mathrm{gs}}\right)^{3 / 2}-\left(V_{\mathrm{bi}}-V_{\mathrm{gs}}\right)^{3 / 2}}{V_{\mathrm{p}}^{3 / 2}}\right]\right\},
$$

where $I_{\mathrm{P}}$ and $V_{\mathrm{P}}$ are the pinch-off current and pinch-off potential, respectively, which can be expressed as

$$
V_{P}=\frac{q N_{\mathrm{D}} a^{2}}{2 \varepsilon}
$$

and

$$
I_{P}=\frac{W_{\mathrm{G}} \mu q^{2} N_{\mathrm{D}}^{2} a^{3}}{6 \varepsilon L_{\mathrm{G}}},
$$

where $q$ is the electron charge and $\varepsilon$ is the dielectric constant of InP. The built-in potential, $V_{\mathrm{bi}}$, of open-gate FETs is determined by the difference in electrochemical potential between the semiconductor and the electrolyte. Therefore, $V_{\mathrm{bi}}$ changes with the surface condition in the open-gate area.

The solid lines in Fig. 3 show the theoretical $I_{\mathrm{ds}}-V_{\mathrm{ds}}$ curves calculated by using eq. (1) when taking the series resistances of both the source and drain contacts into account. As shown in Fig. 3, the experimental data were well reproduced using the calculation with a $V_{\mathrm{bi}}$ of $0.57 \mathrm{eV}$. This indicates that the $I_{\mathrm{ds}}$ currents of open-gate FETs can be well controlled by changing the surface gate bias, $V_{\mathrm{gs}}$.

\subsection{Current response to acid and alkali solutions}

The current response characteristics of InP-based open-gate FETs were investigated for $\mathrm{pH}$-controlled electrolytes. Figures $4(\mathrm{a})$ and $4(\mathrm{~b})$ show the transient behaviors of $I_{\mathrm{ds}}$ measured by successively adding $\mathrm{HCl}$ and $\mathrm{NaOH}$ solutions every minute, respectively. The gate bias $\left(V_{\mathrm{gs}}\right)$ was set at $0 \mathrm{~V}$ during both measurements, and the drain bias $\left(V_{\mathrm{ds}}\right)$ was set at $0.5 \mathrm{~V}$ to evaluate the transfer characteristics in the linear region. As shown in Fig. 4(a), as the pH value decreased from 5.5 to 2.5 with the addition of the acid solution, $I_{\mathrm{ds}}$ increased as if a positive gate bias was additionally applied to the surface. On the other hand, as the $\mathrm{pH}$ value increased from 5.6 to 11.7 with the addition of the alkali solution, $I_{\mathrm{ds}}$ decreased as if a negative gate bias was applied. The response time from both measurements was estimated to be about 300-400 ms, which seems to be limited by the $\mathrm{pH}$ exchange rate in the electrolyte but not by the intrinsic device response. This result is comparable to the ISFETs based on $\mathrm{AlGaAs} / \mathrm{GaAs}^{6)}$ and $\mathrm{AlGaN} / \mathrm{GaN}^{7,8)}$ hetero-structures.

In order to further clarify the relation between the $I_{\mathrm{ds}}$ and $\mathrm{pH}$ values, we plotted the $I_{\mathrm{ds}}$ 
currents obtained here in Fig. 5 as a function of the $\mathrm{pH}$ of the electrolyte. The $I_{\mathrm{ds}}$ curves showed a discontinuous point at a $\mathrm{pH}$ of around 5.6 because the $I_{\mathrm{ds}}$ measurements were interrupted to switch the adding solution between $\mathrm{HCl}$ and $\mathrm{NaOH}$. However, we found that the linear relation between the $I_{\mathrm{ds}}$ and $\mathrm{pH}$ values were obtained in both the acid and alkali regions. As reported by Marin et al. ${ }^{12)}$, the $V_{\mathrm{bi}}$ of n-type InP varies with the surface potential difference caused by the change in $\mathrm{H}^{+}$ ion concentration in the electrolytes. In the present case, the surface potential in the open-gate area changed as a reflection of the $\mathrm{pH}$ values, leading to increases and decreases in the $I_{\mathrm{ds}}$ currents of the open-gate FETs. As shown in Fig. 5, the anomalous behavior of $I_{\mathrm{ds}}$ was observed in a pH range below 3.0, where the $I_{\mathrm{ds}}$ decreased with the $\mathrm{pH}$ values. This is probably because the InP surface in the open-gate area was dissolved into the acid electrolyte with a low $\mathrm{pH}$ value. We found from these results that InP open-gate FETs work as $\mathrm{pH}$ sensors in a wide range from 3.0 to 12.0. This covers the optimum $\mathrm{pH}$ range for various enzymatic reactions, such as lipase $(\mathrm{pH}=4.0-5.0)$, amylase $(\mathrm{pH}=$ 6.7-7.0) and trypsin $(\mathrm{pH}=7.8-8.7)^{13)}$, showing the possibility of the use of InP-based open-gate FETs for biochemical applications.

\section{3 pH sensitivity and selectivity}

In order to clarify the $\mathrm{pH}$ sensitivity of InP open-gate FETs, the relation between the surface potential and the $\mathrm{H}^{+}$concentration was investigated in $\mathrm{pH}$-controlled electrolytes. Figure 6 shows the $\mathrm{pH}$ sensitivity curves obtained for the electrolytes containing $\mathrm{HCl}$ and $\mathrm{H}_{3} \mathrm{PO}_{4}$ solutions. The vertical axis indicates the surface potential difference measured from the reference values obtained at a $\mathrm{pH}$ of 7.0. We found that the surface potentials linearly related to the $\mathrm{pH}$ values for both electrolytes, but there were differences in the slopes of the curves. A pH sensitivity of $44.3 \mathrm{mV} / \mathrm{pH}$ was obtained for the $\mathrm{HCl}$ electrolyte, which was higher than the $37.6 \mathrm{mV} / \mathrm{pH}$ obtained for the $\mathrm{H}_{3} \mathrm{PO}_{4}$ electrolyte. This suggests that the surface potential was affected by not only the $\mathrm{H}^{+}$ions, but also other ions contained in the electrolytes such as the $\mathrm{Cl}^{-}$and $\mathrm{PO}_{4}{ }^{3-}$ ions.

In order to improve the selectivity for the $\mathrm{H}^{+}$ions, the thin silicon nitride $\left(\mathrm{Si}_{3} \mathrm{~N}_{4}\right)$ films were used in the gate area of present FETs. $\mathrm{Si}_{3} \mathrm{~N}_{4}$ film has been commonly used as an ion selective membrane for $\mathrm{pH}$ sensing with Si-based ISFETs ${ }^{5)}$, but has not been used with InP-based ISFETs. Therefore, the gate controllability of $\mathrm{Si}_{3} \mathrm{~N}_{4} / \mathrm{InP}$ FETs in the electrolyte was first investigated by changing the $\mathrm{Si}_{3} \mathrm{~N}_{4}$ thickness. Figure 7 shows the $I_{\mathrm{ds}}-V_{\mathrm{gs}}$ characteristics measured in a PBS electrolyte with a $\mathrm{pH}=7.0$. The thickness of the $\mathrm{Si}_{3} \mathrm{~N}_{4}$ films was measured by using a standard ellipsometric technique. The $I_{\mathrm{ds}}$ currents for $12-\mathrm{nm}$-thick $\mathrm{Si}_{3} \mathrm{~N}_{4}$ films only slightly changed with the gate bias. As the film thickness was decreased, however, the controllability of the $I_{\mathrm{ds}}$ currents recovered. For the $7 \mathrm{~nm}$ thickness, the $I_{\mathrm{ds}}$ currents changed by about $300 \mu \mathrm{A}$ in a bias range from 0 to $-2 \mathrm{~V}$. 
Figure 8 shows the potential sensitivity curves of an InP-based open-gate FET with a $\mathrm{Si}_{3} \mathrm{~N}_{4}$ gate film thickness of $7 \mathrm{~nm}$. We found that there was no significant difference in the sensitivity obtained for the two kinds of electrolytes, which is contrary to the results shown in Fig. 6. The curve slopes were 38.0 and $37.5 \mathrm{mV} / \mathrm{pH}$ for the $\mathrm{HCl}$ and $\mathrm{H}_{3} \mathrm{PO}_{4}$ electrolytes, respectively. These results suggest that the selectivity of $\mathrm{H}^{+}$ions was improved by using the $\mathrm{Si}_{3} \mathrm{~N}_{4}$ films on the open-gate area. However, the $\mathrm{pH}$ sensitivity was smaller than the theoretical value of $58.9 \mathrm{mV} / \mathrm{pH}$ at $24^{\circ} \mathrm{C}$ predicted by using the Nernst equation. One of the possible reasons for this is that high-density states were induced in the energy band gap near the $\mathrm{Si}_{3} \mathrm{~N}_{4} / \mathrm{InP}$ interface. The electric field generated by the adsorbed ions in the open-gate area seems to be partly terminated by the charged interface states. In such a situation, the surface potential can only be slightly changed with the ion concentration in the electrolyte. Various approaches for reducing the interface states have been proposed for the InP, such as sulfur treatments ${ }^{14-16)}$, application of a Si interface layer ${ }^{17)}$, and electrochemical treatment ${ }^{18,19)}$. For example, a large reduction in the interface states was achieved for the $\mathrm{SiN}_{\mathrm{X}} / \mathrm{InP}$ interfaces by using a gaseous $\mathrm{H}_{2} \mathrm{~S}$ treatment, which resulted in recovery of the potential controllability ${ }^{15)}$. Surface passivation is a key issue for the InP-based open-gate FETs, and the optimization of the passivation process would help to further improve their sensitivity.

\section{Conclusions}

We investigated the feasibility of producing liquid-phase sensors that are based on InP open-gate FETs. The open-gate FET clearly exhibited current saturation and a pinch-off behavior in an electrolyte, resulting in a rapid response to the gate bias applied via the electrolyte. We found from a series of sensing measurements that the $I_{\mathrm{ds}}$ currents of open-gate FETs linearly change with the $\mathrm{pH}$ values of electrolytes containing $\mathrm{HCl}, \mathrm{H}_{3} \mathrm{PO}_{4}$, and $\mathrm{NaOH}$ for a wide $\mathrm{pH}$ range from 3.0 to 12.0. The $\mathrm{pH}$ sensitivity was not the same between different electrolytes, showing that the surface potential in the open-gate area was affected by not only $\mathrm{H}^{+}$ions, but also other ions. The selectivity for $\mathrm{H}^{+}$ions was improved by forming $\mathrm{Si}_{3} \mathrm{~N}_{4}$ films on the open-gate area. Further investigation and improvement of the surface passivation process seems to improve both the sensitivity and ion selectivity of liquid-phase chemical sensors based on InP open-gate FETs.

\section{Acknowledgements}

This study was financially supported by the Ozawa and Yoshikawa Memorial Electronics Research Foundation and by a Grant-in-Aid for Young Scientists B (19760208) from the Ministry of Education, Culture, Sports, Science, and Technology of Japan. 


\section{References}

1) P. Bergveld: IEEE Trans. Biomed. Eng. 17 (1970) 70.

2) P. Bergveld: IEEE Trans. Biomed. Eng. 19 (1972) 342.

3) M. Esashi, and T. Matsuo: IEEE Trans. Biomed. Eng. 25 (1978) 184.

4) L. Bousse, N. F. De Rooij, and P. Bergveld: IEEE Trans. Electron Devices 30 (1983) 1263.

5) M.-N. Niu, X.-F. Ding, and Q.-Y. Tong: Sens. Actuators B 37 (1996) 13.

6) S. M. Luber, K. Adlkofer, U. Rant, A. Ulman, A. Gölzhäuser, M. Grunze, D. Schuh, M. Tanaka, M. Tornow, and G. Abstreiter: Physica E 21 (2004) 1111.

7) G. Steinhoff, M. Hermann, W. J. Schaff, L. F. Eastman, M. Stutzmann, and M. Eickhoff: Appl. Phys. Lett. 83 (2003) 177.

8) T. Kokawa, T. Sato, H. Hasegawa, and T. Hashizume: J. Vac. Sci. Technol. B 24 (2006) 1972.

9) H. -I. Chen, Y.-I. Chou, and C.-Y. Chu: Sens. Actuators B 85 (2002) 10.

10) T. Kimura, H. Hasegawa, T. Sato, and T. Hashizume: Jpn. J. Appl. Phys. 45 (2006) 3414.

11) K. Wierzbowska, L. Bideux, B. Adamowicz, and A. Pauly: Sens. Actuators A 142 (2008) 237.

12) F. I.-Marin, C. D.-Chouvy, M. Herlem, J.-L. Sculfort, and A. Etcheberry: J. Electroanal. Chem. 365 (1994) 283.

13) B. Harrow and A. Mazur: Textbook of Biochemistry (Saunders, Philadelphia, PA, 1966) p. 104.

14) H. Oigawa, J. F. Fan, Y. Nannichi, H. Sugahara, and M. Oshima: Jpn. J. Appl. Phys. 30 (1991) L322.

15) A. Kapila, X. Si, and V. Malhotra: Appl. Phys. Lett. 62 (1993) 2259.

16) K. Vaccaro, H. M. Dauplaise, A. Davis, S. M. Spaziani, and J. P. Lorenzo: Appl. Phys. Lett. 67 (1995) 527.

17) H. Takahashi, T. Hashizume, and H. Hasegawa: Appl. Surf. Sci. 123 (1998) 615.

18) C. Kaneshiro, T. Sato, and H. Hasegawa: Jpn. J. Appl. Phys. 38 (1999) 1147.

19) N. Simon, N. C. Quach, A. M. Gonçalves, and A. Etcheberry: J. Electrochem. Soc. 154 (2007) H340. 


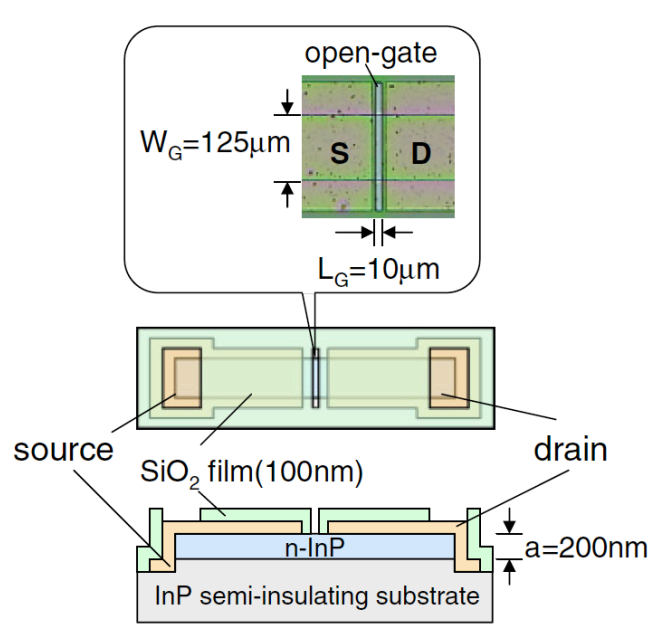

Fig.1 Schematic illustrations and micrograph of InP-based open-gate FET.

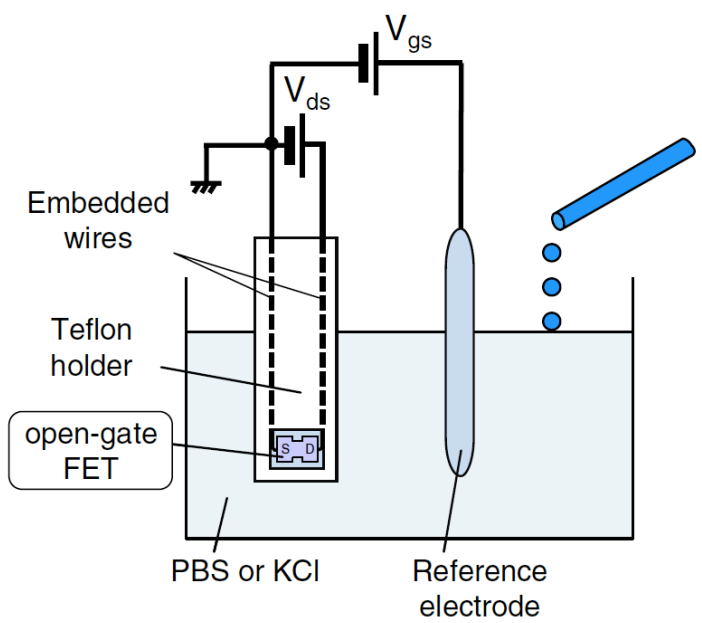

Fig. 2 Experimental setup for sensing measurements.

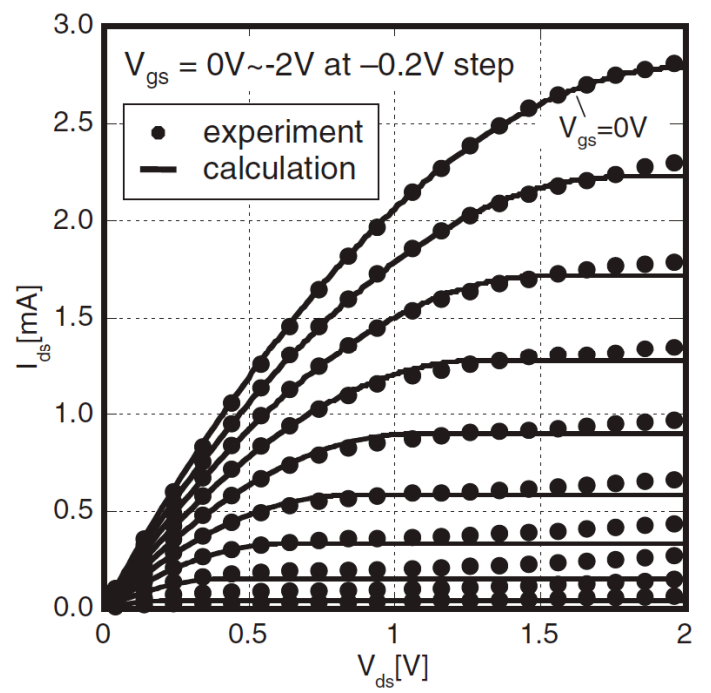

Fig.3 Typical $I_{\mathrm{ds}}-V_{\mathrm{ds}}$ characteristics of open-gate FET measured in PBS electrolyte with $\mathrm{pH}=7.0$.

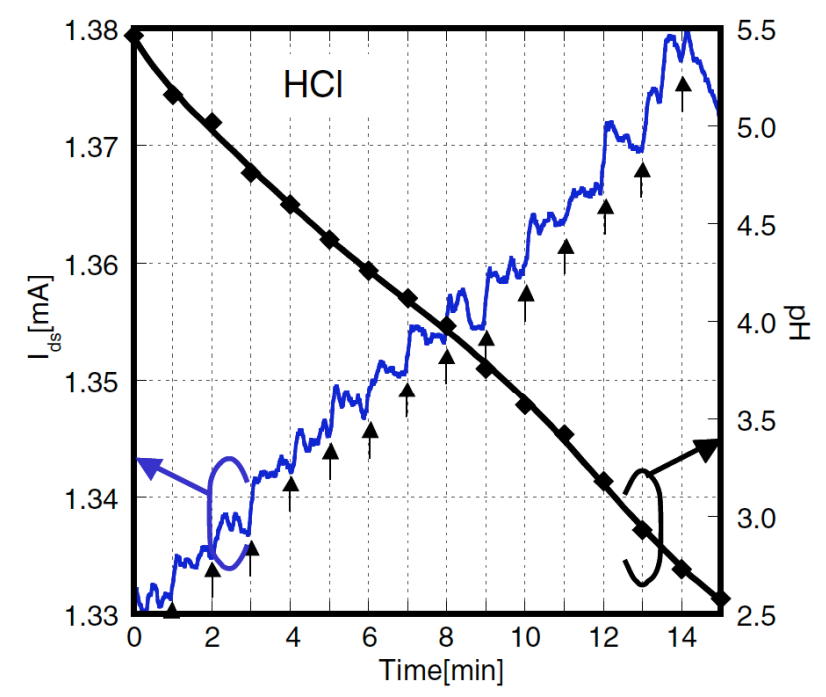

(a)

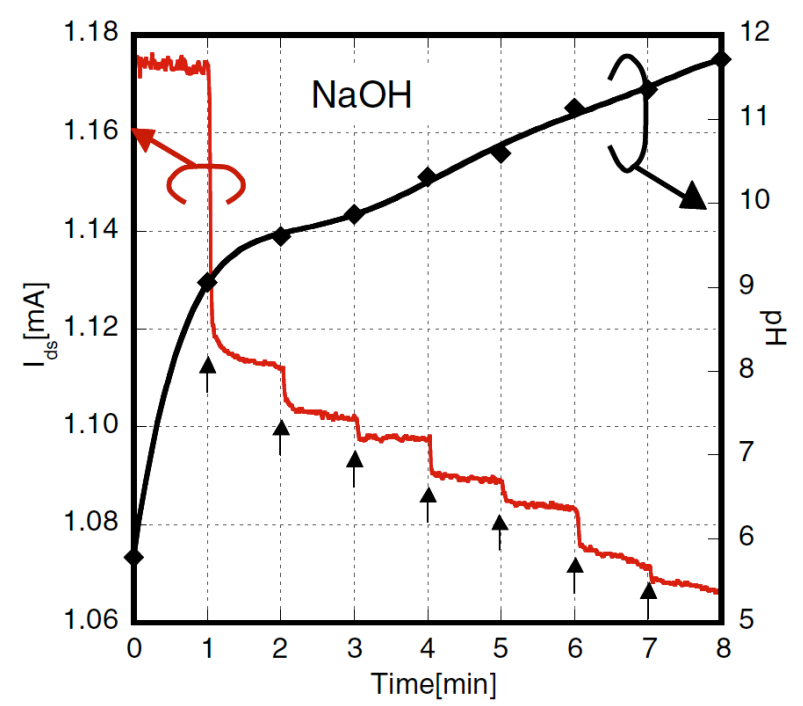

(b)

Fig.4 Transient behaviors of $I_{\mathrm{ds}}$ currents as function of $\mathrm{pH}$ values of two kinds of electrolyte containing (a) $\mathrm{HCl}$ and (b) $\mathrm{NaOH}$ for $\mathrm{pH}$ control. 


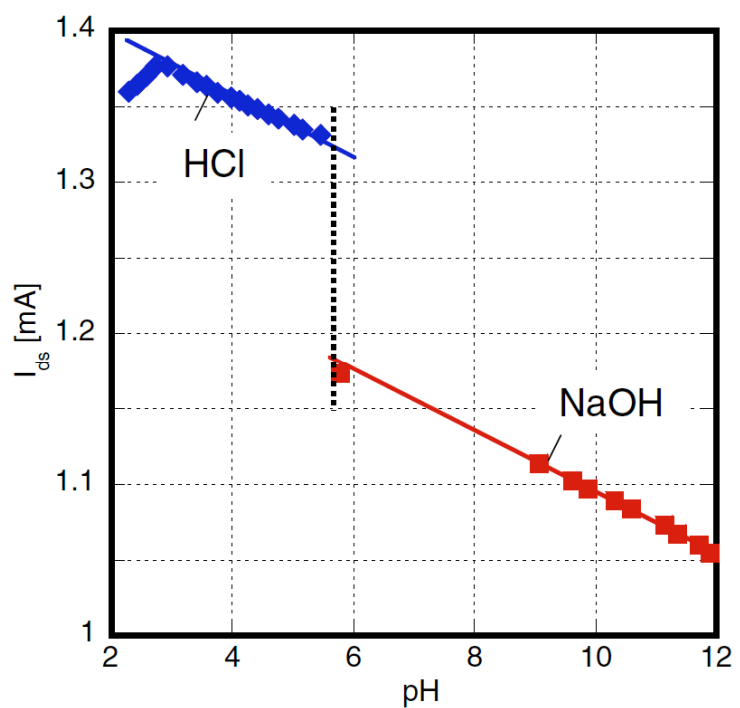

Fig.5 Relation between $I_{\mathrm{ds}}$ and $\mathrm{pH}$ values obtained by adding $\mathrm{HCl}$ and $\mathrm{NaOH}$ solutions.

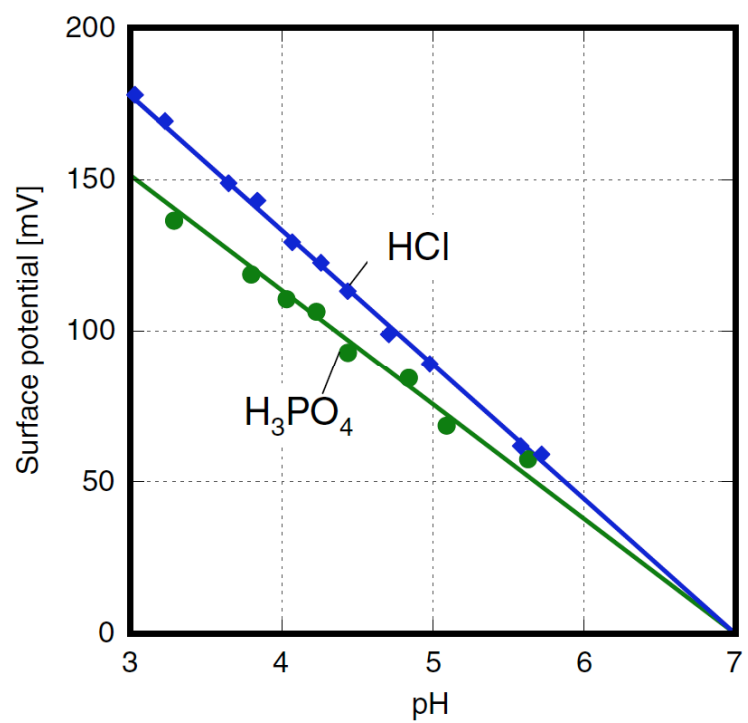

Fig.6 Relation between surface potential and $\mathrm{pH}$ values of electrolytes for InP-based open-gate FETs.
Japanese Journal of Applied Physics, 48 (2009) 091102

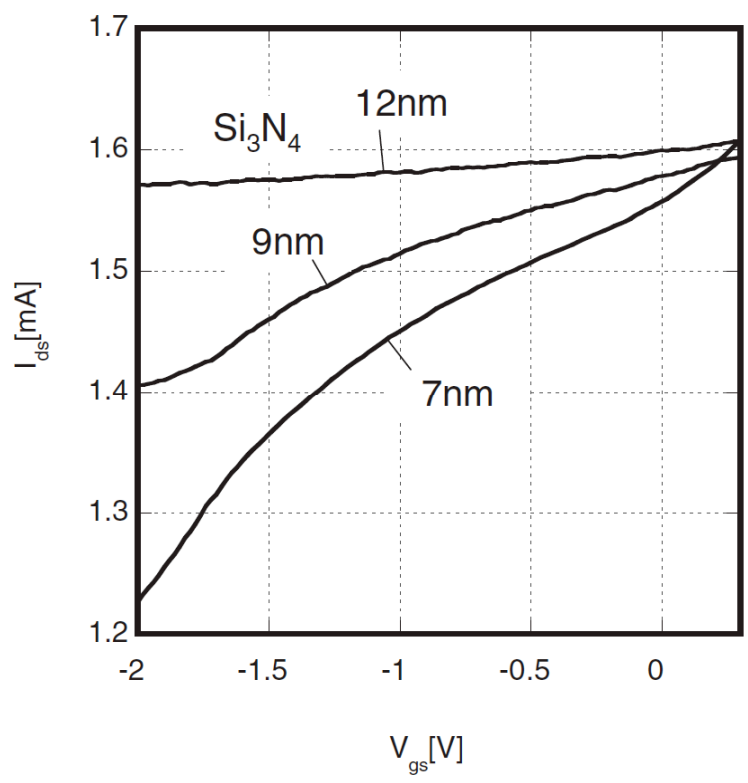

Fig. $7 I_{\mathrm{ds}}-V_{\mathrm{gs}}$ characteristics of open-gate FETs having $\mathrm{Si}_{3} \mathrm{~N}_{4}$ films 7, 9, and $12 \mathrm{~nm}$ thick.

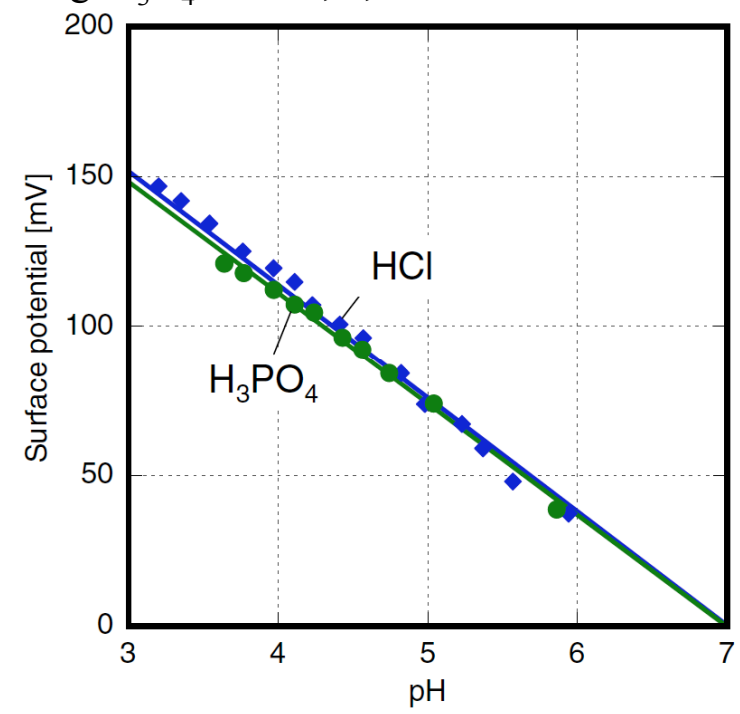

Fig. 8 Relation between surface potential and $\mathrm{pH}$ values of electrolytes for InP-based open-gate FETs having $\mathrm{Si}_{3} \mathrm{~N}_{4}$ films $7 \mathrm{~nm}$ thick. 